\title{
Cytoarchitecture of Pneumotaxic Integration of Respiratory and Nonrespiratory Information in the Rat
}

\author{
Gang Song, Yunguo Yu, and Chi-Sang Poon \\ Harvard University-Massachusetts Institute of Technology Division of Health Sciences and Technology, Massachusetts Institute of Technology, \\ Cambridge, Massachusetts 02139
}

\begin{abstract}
The "pneumotaxic center" in the Kölliker-Fuse and medial parabrachial nuclei of dorsolateral pons (dl-pons) plays an important role in respiratory phase switching, modulation of respiratory reflex, and rhythmogenesis. Recent electrophysiological and neural tracing data implicate additional pneumotaxic nuclei in (and a broader role for) the dl-pons in integrating respiratory and nonrespiratory information. Here, we examined the cytoarchitecture of the greater pneumotaxic center and its integrating function by using combined extracellular recording and juxtacellular labeling of unit respiratory rhythmic neurons in dl-pons in urethane-anesthetized, vagotomized, paralyzed, and servo-ventilated adult Sprague Dawley rats. Perievent histogram analysis identified four major types of neuronal discharge patterns: inspiratory, expiratory (with three subdivisions), inspiratory-expiratory, and expiratory-inspiratory phase spanning, sometimes with mild tonic background activity. Most recorded neurons were localized in the Kölliker-Fuse and medial parabrachial nuclei, but some were also found in lateral parabrachial nucleus, intertrigeminal nucleus, principal trigeminal sensory nucleus, and supratrigeminal nucleus. The majority of labeled neurons had large and spatially extended dendritic trees that spanned several of these dl-pons subnuclei, often with terminal dendrites ending in the ventral spinocerebellar tract. The distal sections of the primary and higher-order dendrites exhibited rich varicosities, sometimes with dendritic spines. Axons of some labeled neurons were traced all the way to the ventrolateral pons (vl-pons). These findings extend and generalize the classical definition of the pneumotaxic center to include extensive somaticaxonal- dendritic integration of complex descending and ascending respiratory information as well as nociceptive and possibly musculoskeletal and trigeminal information in multiple dl-pons and vl-pons structures in the rat.
\end{abstract}

Key words: pneumotaxic center; dorsolateral pons; ventrolateral pons; neural control of breathing; juxtacellular labeling; ventral spinocerebellar tract; trigeminal nuclei

\section{Introduction}

Since the seminal work of T. Lumsden eight decades ago that defined the "pneumotaxic center" in cats (Lumsden, 1923), the pons has been extensively studied for its roles in inspiratory phase switching, modulation of respiratory reflex, and generation of independent pontine rhythm (for review, see Alheid et al., 2004). Electrophysiological studies in cats and other animal species have identified the pneumotaxic center with a group of respiratory rhythmic neurons (pontine respiratory group) primarily within the Kölliker-Fuse (KF) and medial parabrachial (mPB) nuclei of dorsolateral pons (dl-pons), in which focal lesion in bivagotomy causes apneusis and stimulation facilitates expiration (for review, see von Euler, 1986; Dick et al., 1995). Neural tracing studies reveal that the dl-pons has intensive reciprocal connections with the ventral (VRG) and dorsal (DRG) respiratory groups in medulla, which mediate information from respiratory central pattern generator and afferents from pulmonary slowly and rapidly adapting stretch receptors, respectively (for review, see Ezure,

\footnotetext{
Received July 21, 2005; revised 0ct. 17, 2005; accepted Nov. 10, 2005.

This work was supported by National Institutes of Health Grants HL67966 and HL72849. We thank Dr. M. Aoki for reading this manuscript and S. M. MacDonald for skillful technical assistance.

Correspondence should be addressed to Chi-Sang Poon, Harvard University-Massachusetts Institute of Technology Division of Health Sciences and Technology, Building 56-046, Massachusetts Institute of Technology, 77 Massachusetts Avenue, Cambridge, MA 02139. E-mail: cpoon@mit.edu.

DOI:10.1523/JNEUROSCI.3029-05.2006

Copyright $\odot 2006$ Society for Neuroscience $\quad 0270-6474 / 06 / 260300-11 \$ 15.00 / 0$
}

2004; Song and Poon, 2004). In addition, it receives projections originating from central chemoreceptors in the medullary ventral surface (Mulkey et al., 2004).

Recent studies in rats suggest that dl-pons is also involved in other respiratory-related functions, including expiratory phaseswitching (Chamberlin and Saper, 1994), sleep apnea (Radulovacki et al., 2004), modulation of respiration by somatic movement (Potts et al., 2005) or nociceptive inputs (Jiang et al., 2004), learning and memory behavior of Hering-Breuer reflex (Poon and Siniaia, 2000; Siniaia et al., 2000; Song and Poon, 2004), and the protective diving reflex (Dutschmann and Herbert, 1996). Many of these functions involve other dl-pons loci beyond the $\mathrm{mPB}-\mathrm{KF}$ complex, such as the lateral parabrachial (lPB) nucleus, intertrigeminal nucleus (IT), and ventrolateral principal trigeminal sensory nucleus (Pr5). In addition, various subregions of the ventrolateral pons (vl-pons), such as the A5 noradrenergic neuron group and the lateral reticular formation, have been shown to modulate the respiratory rhythm (Jodkowski et al., 1994, 1997; Jacquin et al., 1996; Borday et al., 1997). The variety of respiratory-related functions demonstrated in varying pontine loci suggests an extended organization of the pneumotaxic center in integrating multiplex physiological information. Such widespread integrative mechanisms cannot be elucidated readily using traditional electrophysiological or neural tracing approaches alone as in most previous studies.

In the present study, we applied the juxtacellular labeling tech- 
nique (Pinault, 1996) in conjunction with extracellular unit recording to discern the cytoarchitecture of functionally identified pneumotaxic neurons, defined herein as respiratory rhythmic neurons in $\mathrm{mPB}-\mathrm{KF}$ and other dl-pons regions. The pneumotaxic neurons so identified displayed a wide range of respiratorymodulated discharge patterns and revealed interesting morphological features at the somatic, axonal, and dendritic levels, which provide a new dimension for understanding the mechanisms of pneumotaxic integration of respiratory and nonrespiratory information. The results provide strong support for an extended definition of the pneumotaxic center to include a widespread region in dl-pons and ventrolateral pons (vl-pons) involved in the modulation of the respiratory rhythm by respiratory and other inputs.

Parts of this work have been published previously in abstract form (Song and Poon, 2003).

\section{Materials and Methods}

Animal preparation. Experiments were conducted on 19 adult male Sprague Dawley rats (Charles River Laboratories, Wilmington, MA) weighing 290-350 g. All experimental protocols were reviewed and approved by the Massachusetts Institute of Technology Committee on Animal Care in accordance with published guidelines.

After injection with atropine sulfate $(0.025 \mathrm{mg}$, s.c.) to reduce tracheal secretions, the rat was anesthetized with urethane (1.5 g/kg i.p.; Sigma, St. Louis, MO), tracheostomized, paralyzed with pancuronium bromide (initial dose $0.5 \mathrm{mg}$, i.v., supplemented every hour at $0.1 \mathrm{mg}$, i.v., administered through a femoral catheter; Sigma), and servo-ventilated (AVS-1; CWE, Ardmore, PA) on $40 \%$ oxygen in medical-grade air with body temperature maintained at $36 \pm 0.5^{\circ} \mathrm{C}$ by a thermostat (TC-831; CWE). To minimize ventilation-induced movements, large bilateral pneumothorax was produced, and an end-expiratory pressure of $0.5-1 \mathrm{~cm} \mathrm{H}_{2} \mathrm{O}$ was applied to distend the lungs. End-tidal $\mathrm{CO}_{2}$ was monitored with an infrared $\mathrm{CO}_{2}$ monitor (CapStar-100; CWE) and maintained at $5.0-5.5 \%$. Throughout the experiment, a supplemental dose of urethane $(1 / 10$ of initial dosage) was given intravenously whenever a pinch of the hindpaw caused changes in pupil size or respiratory frequency.

The right phrenic nerve and both vagi were isolated and severed at the cervical level with a ventral approach. The animal's head was then immobilized on a stereotaxic frame (KOPF 1430; David Kopf Instruments, Tujunga, CA) in a tilted position with bregma $1.5 \mathrm{~mm}$ higher than lambda to approach the dl-pons without penetrating the transverse venous sinus. A craniotomy (diameter of $0.5 \mathrm{~cm}$ ) was performed at the interaural level on the dorsal surface of the skull on the left side. Dura and pia were carefully removed, and the exposed brain surface was covered with petroleum jelly. The isolated right phrenic nerve was exposed from dorsal approach and mounted on a bipolar platinum wire electrode (Frederick Haer Company, Bowdoinham, ME). Phrenic discharges were amplified (CyberAmp 380; Axon Instruments, Union City) and recorded on a computer through a digital interface (LabView; National Instruments, Austin, TX) at a sampling rate of $10 \mathrm{kHz}$. In some experiments, the phrenic discharges were integrated with a Paynter filter (time constant of $15 \mathrm{~ms}$ ).

Extracellular recording and juxtacellular labeling. Extracellular unit recording and juxtacellular labeling were achieved by using a glass microelectrode fabricated from borosilicate pipette (outer diameter of $1.2 \mathrm{~mm}$; inner diameter of $0.6 \mathrm{~mm}$ ) on a Sutter Instruments (Novato, CA) P-87 puller. The microelectrode was backfilled with $1.5 \%$ Neurobiotin (biotinamide hydrochloride; Vector Laboratories, Burlingame, CA) in $0.5 \mathrm{M}$ $\mathrm{NaCl}$. The external tip diameter of the microelectrode was $1.1-2.2 \mu \mathrm{m}$. Once inserted into the brain, the impedance was $15-35 \mathrm{M} \Omega$ as measured with an AxoClamp 2B amplifier (Axon Instruments) under bridge mode. The microelectrode was inserted stereotaxically into the dl-pons, with coordinates of -0.40 (caudal) to $+0.2 \mathrm{~mm}$ (rostral) to lambda, $1.8-2.8$ $\mathrm{mm}$ lateral to midline, and 7-9.0 mm below lambda surface (Paxinos and Watson, 1986). Unit discharge was preamplified (AxoClamp 2B; Axon Instruments) under bridge mode and further amplified (CyberAmp 380;

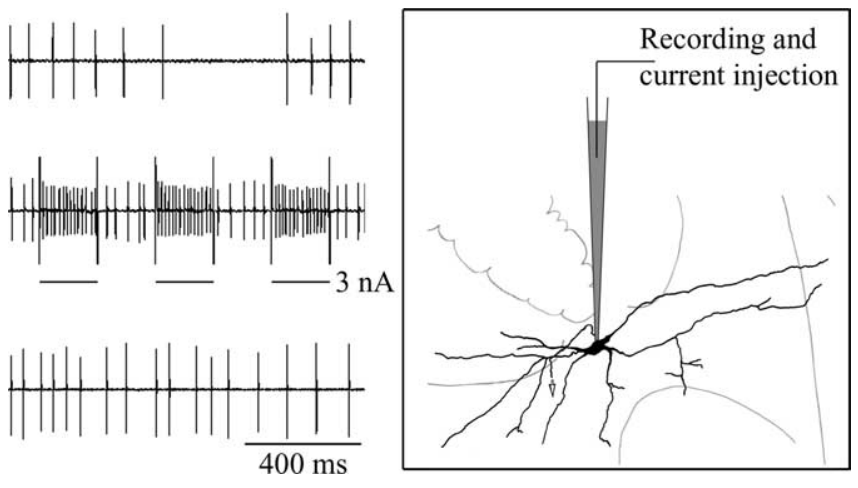

Figure 1. Juxtacellular labeling and extracellular recording technique. Left, Unit discharge of a pontine respiratory neuron before, during, and after juxtacellular labeling (from top to bottom). Note entrainment of unit discharge during juxtacellular current injection and the recovery of spontaneous discharge after injection. Right, Schematic drawing showing the position of the micropipette juxtaposed with the neuron being recorded. The tip of the micropipette presumably "touched" the neuron membrane without penetration during current injection.

Axon Instruments) to a total of 2000-5000 folds, digitized, and recorded on a computer as with phrenic discharge. Once respiratory unit discharges were found, the depth of the electrode was carefully adjusted to obtain spikes with the highest signal-to-noise ratio. The unit recording was then stabilized for $10 \mathrm{~min}$ and evaluated for its phase relation with phrenic discharge.

To obtain juxtacellular labeling of the recorded neuron, positive current pulses ( $200 \mathrm{~ms}$ on and $200 \mathrm{~ms}$ off, $2.5 \mathrm{~Hz}$ ) were injected through the same recording electrode to entrain the unit discharge (Fig. 1). The current intensity was $2-3 \mathrm{nA}$ at the beginning and was carefully adjusted to keep the unit entrained for 8-25 min. After current injection, the neuron was deemed healthy if it resumed with discharge similar to control.

To avoid ambiguity in subsequent neuronal reconstruction, usually no more than three neurons were current injected in each rat, and they were separated by at least $0.3 \mathrm{~mm}$. If another unit was detected at the same recording site during or after current injection, the data were discarded.

Perievent histogram analysis. Because of the relatively low discharge frequencies of pneumotaxic neurons and their diverse and irregular discharge patterns, visual discrimination of respiratory-modulated neuronal activity is sometimes difficult. Accordingly, perievent analysis in relation to the respiratory rhythm was performed on all unit recordings. Briefly, the neuronal spikes were discriminated, extracted, and converted to time-stamp signals using offline spike sorting software (OfflineSorter; Plexon, Dallas, TX). Perievent histograms (PEHs) of the time-stamp signals were then plotted (NeuroExplorer; Nex Technologies, Littleton, MA) against the inspiratory/expiratory event markers extracted from phrenic discharges. Respiratory-modulated neuronal activity was indicated by the periodic recurrence of peaks and troughs (above or below mean activity at $95 \%$ confidence level) in the PEH in synchrony with the respiratory rhythm.

Histochemistry and neuronal reconstruction. After juxtacellular labeling of neurons, the rat was kept alive for additional 2-3 $\mathrm{h}$ before it was killed with an additional dose of urethane $(1.0 \mathrm{~g} / \mathrm{kg}$, i.v. $)$ and perfused transcardially with $300 \mathrm{ml}$ of heparinized saline, followed by $300 \mathrm{ml}$ of chilled (at $4^{\circ} \mathrm{C}$ ) $4 \%$ paraformaldehyde in $0.1 \mathrm{~m}$ PBS. The brain was removed, postfixed in $4 \%$ paraformaldehyde for $48 \mathrm{~h}$, blocked, and cut into consecutive coronal sections (thickness of $80 \mu \mathrm{m}$ ) on a vibratome in accordance with a standard rat brain atlas (Paxinos and Watson, 1986). Sections were rinsed in $0.05 \mathrm{M}$ PBS containing $0.3 \%$ Triton X-100 (PBS-T) and incubated in $\mathrm{ABC}$ reagent [standard $\mathrm{ABC}$ kit (Vector Laboratories), 1:200 dilution with $0.05 \mathrm{~m}$ PBS-T] for $4 \mathrm{~h}$ at room temperature. The sections were then rinsed again and developed with standard $\mathrm{DAB}(0.05 \% \mathrm{DAB}$ and $0.0015 \% \mathrm{H}_{2} \mathrm{O}_{2}$ in $0.05 \mathrm{M}$ PBS-T) or nickel-intensified DAB $(0.05 \%$ DAB, $0.1 \% \mathrm{NiCl}_{2}$, and $0.0015 \% \mathrm{H}_{2} \mathrm{O}_{2}$ in $0.05 \mathrm{M}$ TBS containing Triton $\mathrm{X}-100)$ methods. Sections were mounted onto gelatin-coated slides and lightly counterstained with Neutral Red for Nissl body staining to aid in identification of neuroanatomic structures. 
Table 1. Morphofunctional characteristics of pneumotaxic neurons revealed by juxtacellular labeling

\begin{tabular}{|c|c|c|c|c|c|c|c|}
\hline Functional subtype & $\begin{array}{l}\text { Soma size } \\
(\mu \mathrm{m})\end{array}$ & Soma loci & $\begin{array}{l}\text { Dendritic tree } \\
(\mu \mathrm{m})\end{array}$ & Orientation of dendritic tree & Dendritic type & Dendritic spines & Axon projection \\
\hline $\mathrm{IE}_{1}$ & $19.4 \times 12.8$ & KF & $425 \times 160$ & Dorsoventral & I & - & vl-pons \\
\hline $\mathrm{eE}_{2}$ & $24.2 \times 11$ & $\mathrm{mPB}$ & $350 \times 200$ & Mediolateral & I & - & $?$ \\
\hline $\mathrm{El}_{2}^{2}$ & $22 \times 13.2$ & $\operatorname{Pr} 5$ & $230 \times 110$ & Dorsoventral & I & - & vl-pons \\
\hline $\mathrm{El}_{5}$ & $23.1 \times 8.8$ & $55 \mathrm{M}$ & $460 \times 220$ & Mediolateral & I & - & $?$ \\
\hline $\mathrm{I}_{1}$ & $19.8 \times 13.2$ & IPB & $720 \times 550$ & Dorsoventral & $\|$ & - & vl-pons \\
\hline $\mathrm{I}_{2}$ & $23.1 \times 8.8$ & KF & $670 \times 220$ & Dorsolateral-ventromedial & $\|$ & - & vl-pons \\
\hline $\mathrm{IE}_{2}$ & $19.8 \times 13.2$ & KF & $500 \times 370$ & No preferred orientation & $\|$ & + & $?$ \\
\hline LateE $_{1}$ & $28.6 \times 11$ & $\mathrm{mPB}$ & $650 \times 150$ & Mediolateral & $\|$ & - & $?$ \\
\hline LateE $_{2}$ & $23.1 \times 13.2$ & KF & $600 \times 420$ & No preferred orientation & $\|$ & - & vl-pons \\
\hline $\mathrm{El}_{1}$ & $23.1 \times 13.2$ & KF & $1000 \times 360$ & Mediolateral & $\|$ & - & vl-pons \\
\hline $\mathrm{El}_{3}$ & $17.6 \times 16.5$ & $\operatorname{Pr} 5$ & $550 \times 450$ & No preferred orientation & $\|$ & + & vl-pons \\
\hline $\mathrm{El}_{4}$ & $19.8 \times 13.2$ & $\mathrm{mPB}$ & $750 \times 300$ & Mediolateral & $\|$ & + & $?$ \\
\hline
\end{tabular}

+ and -, Dendritic spines identified (+) or not identified $(-) ;$ ?, axonal process was traced for only a short distance and could not be confirmed; eE, early-expiratory neuron; LateE, late-expiratory neurons; l, expiratory-inspiratory phase-spanning neuron; I, inspiratory neuron; IE, inspiratory- expiratory phase-spanning neuron; El, expiratory-inspiratory phase-spanning neuron; $55 \mathrm{M}$, supratrigeminal nucleus.

Labeled neurons in each section were observed and drawn with a light microscope (BH-2; Olympus Opticalm Tokyo, Japan) equipped with a drawing tube. Axons were identified under oil lens (100×) according to the following criteria: 1 , absence of varicosities or spines; 2 , thin and constant diameter and could be traced for a long distance $(>0.5 \mathrm{~mm})$. The soma, dendrites, and axon of each neuron were drawn under a $20 \times$ objective lens and reconstructed by collating the drawings from three to seven consecutive sections. Because the dendritic trees of neurons in $\mathrm{mPB}$ and $\mathrm{KF}$ tended to extend in mediolateral or dorsoventral directions instead of rostrocaudal direction, dendrites of neurons that we labeled did not extend beyond seven coronal $80 \mu \mathrm{m}$ sections. Neuroanatomic structures surrounding each neuron were delineated based on Nissl body staining of the section in which the labeled soma was situated. All drawings were scanned into a computer at a resolution of 600 dots per inch and edited with Photoshop software (Adobe Systems, San Jose, CA). To show the distribution pattern of pontine respiratory neurons relative to the established subnuclei of dl-pons, all labeled neurons were plotted onto three standard plates (Plates 52-54) of the Paxinos and Watson (1986) brain atlas. Loci of other respiratory neurons were deduced from their stereotaxic coordinates relative to the labeled neurons and similarly plotted. Photomicrographs of somata (under $40 \times$ objective lens) and dendrites (under $100 \times$ oil lens) were taken with a Sony (Tokyo, Japan) DFW-SX900 CCD digital camera and input into a computer. Photos were then edited and converted into grayscale image with Photoshop software. The brightness was adjusted and the contrast was enhanced when necessary.

\section{Results}

Of the 40 pneumotaxic neurons that were extracellularly recorded and juxtacellularly current injected, 22 (55\%) were retrieved histologically. All of the 22 neurons were current entrained for $>8 \mathrm{~min}$ and resumed normal firing afterward. Among them, 12 showed Golgi-like staining that allowed the reconstruction of the entire (or almost entire) dendritic trees, with the axonal paths of seven neurons being traced for relatively long distances $(>0.5 \mathrm{~mm})$. The discharge patterns and salient morphological characteristics of the 12 well labeled neurons are summarized in Table 1; a complete account of all recorded and/or labeled neurons is given below.

\section{Pneumotaxic neurons display diverse respiratory-modulated discharge patterns}

Quantitative PEH analysis of the recorded pneumotaxic neurons $(n=40)$ revealed four distinct types of discharge patterns (for examples from all labeled neurons and selected recorded neurons, see Fig. 2): inspiratory (I), inspiratory-expiratory phase spanning (IE), expiratory (E), and expiratory-inspiratory phase spanning (EI). Within each functional type, the neuronal dis-

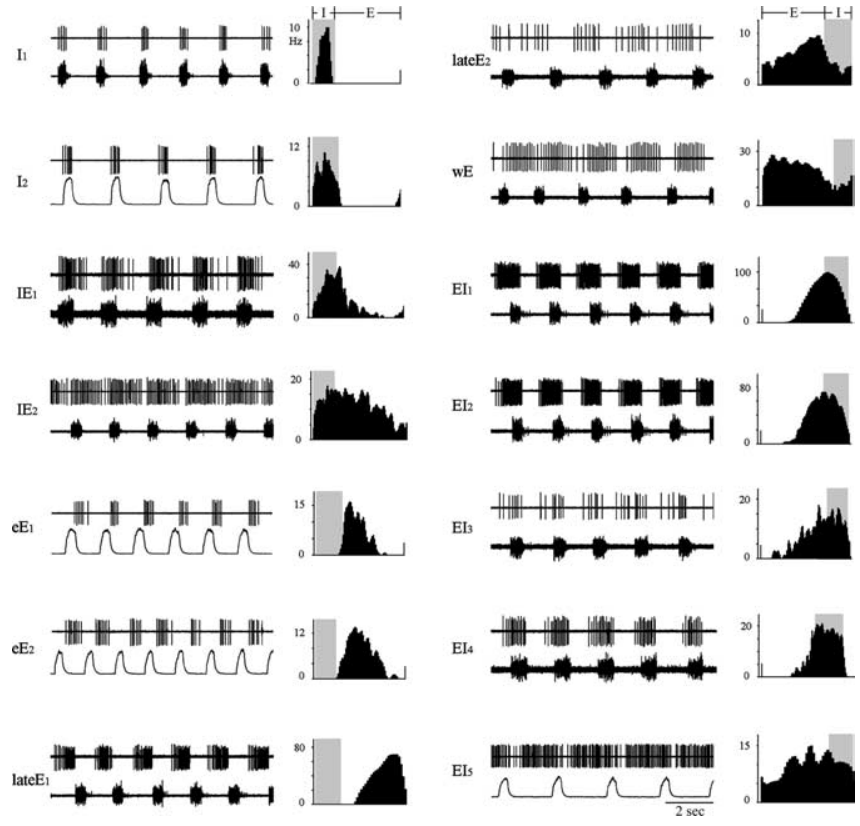

Figure 2. Discharge patterns of 12 labeled and two unlabeled pneumotaxic neurons ( $\mathrm{eE}_{1}$ and wE). Displayed for each neuron are as follows: left, unit discharge (top trace) and corresponding phrenic discharge or integrated phrenic discharge (bottom trace); right, perievent histogram of unit discharge (in spikes per second). E, Expiratory phase; I, inspiratory phase (shaded intervals in right panels); $I_{1}, I_{2}$, inspiratory neurons; $I_{1}, I_{2}$, inspiratory- expiratory phase-spanning neurons; $\mathrm{eE}_{1}, \mathrm{eE}_{2}$, early-expiratory neurons; LateE $_{1}$, LateE $\mathrm{E}_{2}$, late-expiratory neurons; $w \mathrm{E}$, whole-phase expiratory neuron; $\mathrm{El}_{1}-\mathrm{El}_{5}$, expiratory-inspiratory phase-spanning neurons. Note the presence of tonic background activity in some neurons $\left(\mathrm{IE}_{2}\right.$, late $\left.\mathrm{E}_{2}, \mathrm{WE}, \mathrm{EI}_{5}\right)$.

charge patterns were not uniform but could vary considerably from neuron to neuron, indicating a high degree of polymorphism. Although the majority of pneumotaxic neurons were phasic neurons with distinct discharging period and silent period (Fig. 2, I 1 ), some neurons showed seemingly sporadic or tonic background discharges with no consistently discernible silent period. Traditionally, the latter are called "tonic" or "nonphasic" respiratory neurons. Here, the $\mathrm{PEH}$ analysis revealed that their discharge patterns comprised a dominant respiratory phasic component superimposed on tonic low-frequency background discharge (Fig. 2, lateE ${ }_{2}$, wE).

\section{Inspiratory neurons}

A total of 15 inspiratory neurons were recorded from dl-pons. They were phasic neurons with either augmenting or constant 
discharge pattern during the inspiratory phase. A few neurons also showed some spikes in late expiratory or preinspiratory phase. Two neurons of this group were labeled and reconstructed $\left(\mathrm{I}_{1}\right.$ and $\left.\mathrm{I}_{2}\right)$.

\section{Inspiratory-expiratory phase-spanning neurons}

Three inspiratory-expiratory phase-spanning neurons were recorded from KF. They displayed an augmenting or constant discharge pattern during the inspiratory phase and continued into the early one-third to two-thirds of the expiratory phase with a decrementing pattern. Two of them were labeled and reconstructed $\left(\mathrm{IE}_{1}\right.$ and $\left.\mathrm{IE}_{2}\right)$.

\section{Expiratory neurons}

A total of 15 expiratory neurons were recorded from the dl-pons. Based on PEH analysis, they were further classified as follows: (1) early-expiratory $(\mathrm{eE})$ or post-inspiratory neurons, which discharged during the first one-third to two-thirds of the expiratory phase with a decrementing pattern (Fig. 2, $\mathrm{eE}_{1}, \mathrm{eE}_{2}$ ); (2) lateexpiratory (lateE) neurons, which discharged during the late twothirds to one-half of expiratory phase with an augmenting pattern (Fig. 2, lateE $\mathrm{E}_{1}$, late $\left.\mathrm{E}_{2}\right)$; and (3) whole-phase expiratory ( $\mathrm{wE}$ ) neurons, which discharged during the entire or almost entire expiratory phase with a constant or decrementing pattern (Fig. 2, $\mathrm{wE})$. Three expiratory neurons were labeled and reconstructed $\left(\mathrm{eE}_{2}\right.$, lateE $\mathrm{E}_{1}$, and lateE $\left.\mathrm{E}_{2}\right)$.

\section{Expiratory-inspiratory phase-spanning neurons}

Seven expiratory-inspiratory phase-spanning neurons were recorded in the dl-pons. Six of them were phasic neurons that started firing at the late two-thirds of the expiratory phase and continued until the end of the next inspiratory phase (sometimes trailing into the post-inspiratory phase). They had bell-shaped discharge patterns that peaked at late-expiratory or earlyinspiratory phases around the expiratory-to-inspiratory phase transition. The other two neurons showed augmenting discharge patterns that reached peak frequency at late inspiration. Five neurons of this group were labeled and reconstructed $\left(\mathrm{EI}_{1}-\mathrm{EI}_{5}\right)$.

\section{The pneumotaxic center includes lateral parabrachial and trigeminal nuclei}

The relative loci of all recorded pneumotaxic neurons are depicted collectively on standard plates for dl-pons (Fig. 3); the precise loci of the individual labeled neurons against Nissl body staining of neighboring structures are depicted in Figures 4 and 5. More often than not, the expiratory neurons were located medially in the $\mathrm{mPB}$, whereas the inspiratory and phase-spanning neurons were encountered laterally in the KF nucleus. Importantly, although our recordings targeted mostly respiratory neurons in or around these traditional pneumotaxic regions, some respiratory neurons were also recorded in $\mathrm{PB}$ and pontine trigeminal nuclei, including IT, dorsal margin of Pr5, and supratrigeminal nucleus (Su5).

\section{Pneumotaxic dendritic domains invade respiratory and nonrespiratory areas in dl-pons}

Juxtacellularly labeled pneumotaxic neurons generally displayed two types of dendritic trees (type I and type II), which can be distinguished based on their size and the number of pontine structures with which they made contact.

\section{Small and localized dendritic tree (type I)}

Consistent with the traditional view of the pneumotaxic center, four juxtacellularly labeled neurons (type I) (Fig. 4) showed rel-
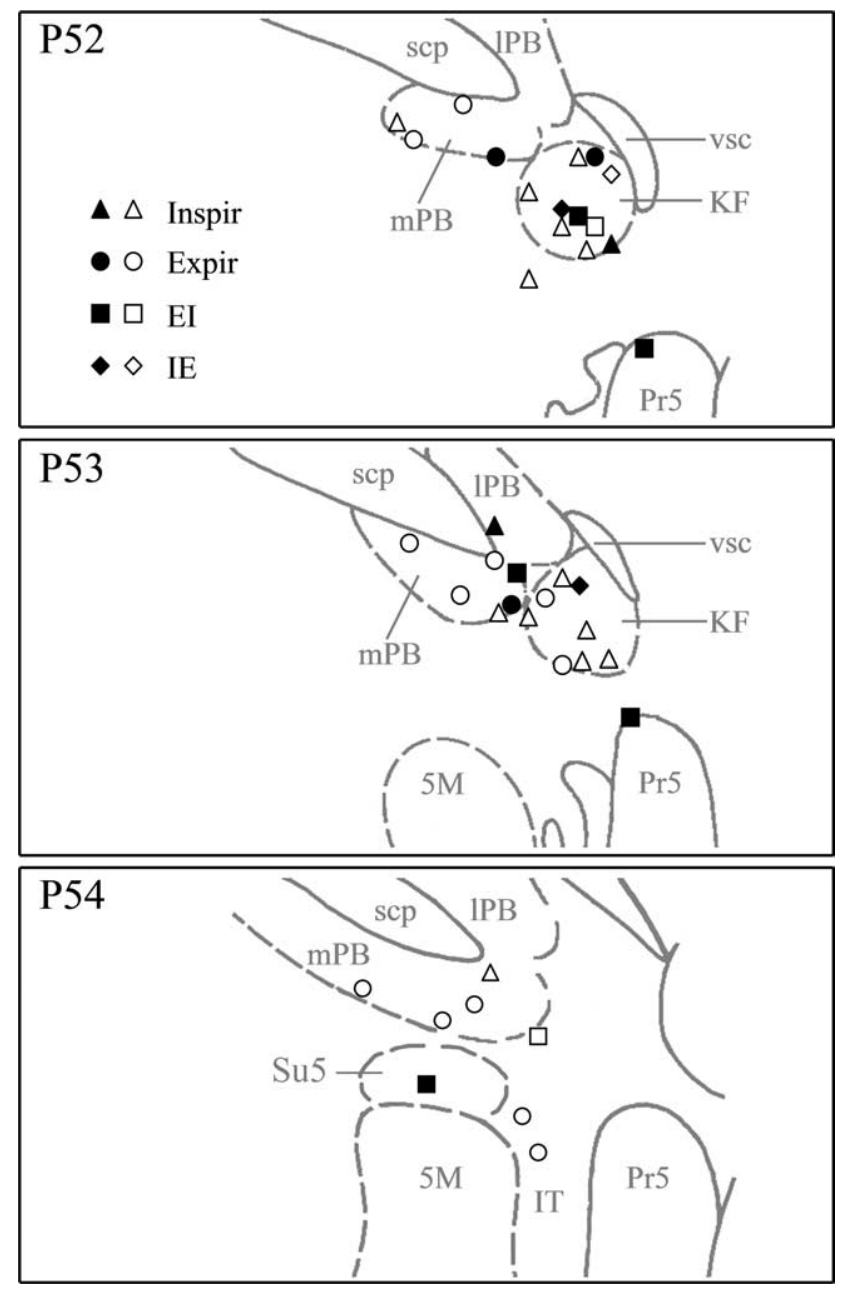

Figure 3. Schematic drawings showing distribution of pneumotaxic neurons $(n=40)$. Four types of phasic discharge patterns were classified based on PEH analysis: inspiratory (Inspir; $n=$ 15), inspiratory- expiratory phase-spanning (IE; $n=3)$, expiratory (Expir; $n=15)$, and expiratory-inspiratory phase-spanning (El; $n=7$ ). Locations of labeled neurons (filled symbols) were directly plotted onto three standard plates (Paxinos and Watson, 1986, their plates 52 54) according to their loci as determined histologically. Locations of unlabeled neurons (open symbols) were deduced according to their stereotaxic coordinates relative to the labeled neurons. Note that most pneumotaxic neurons were located in $\mathrm{KF}$ and $\mathrm{mPB}$, but some were also found in IPB, IT, SU5, and Pr5. 5M, Trigeminal motor nucleus; scp, superior cerebellar peduncle.

atively small and restricted dendritic trees that were either confined within the principal pneumotaxic subnuclei in which the somata were located or entered shortly into adjacent structures. The average dimensions of the dendritic trees were $367 \times 173 \mu \mathrm{m}$.

Interestingly, all neurons in this group demonstrated axonlike fine processes (see criteria above, Histochemistry and neuronal reconstruction), two of which could be traced for relatively long distances $(\sim 1 \mathrm{~mm})$ (Fig. $\left.4, \mathrm{IE}_{1}, \mathrm{EI}_{2}\right)$. Because axons are much thinner, and hence more difficult, to fill than dendrites, the small and restricted dendritic reconstructions likely reflect the genuine morphology of this group of neurons rather than poor labeling.

\section{Large and spatially extended dendritic tree (type II)}

In contrast to the traditional type I neurons, the majority $(n=8)$ of pneumotaxic neurons recovered by juxtacellular labeling had large and spatially extended dendritic trees (type II) (Fig. 5). Typically, the dendrites intruded at least two adjacent structures, including traditional pneumotaxic areas such as $\mathrm{mPB}$ or KF nu- 


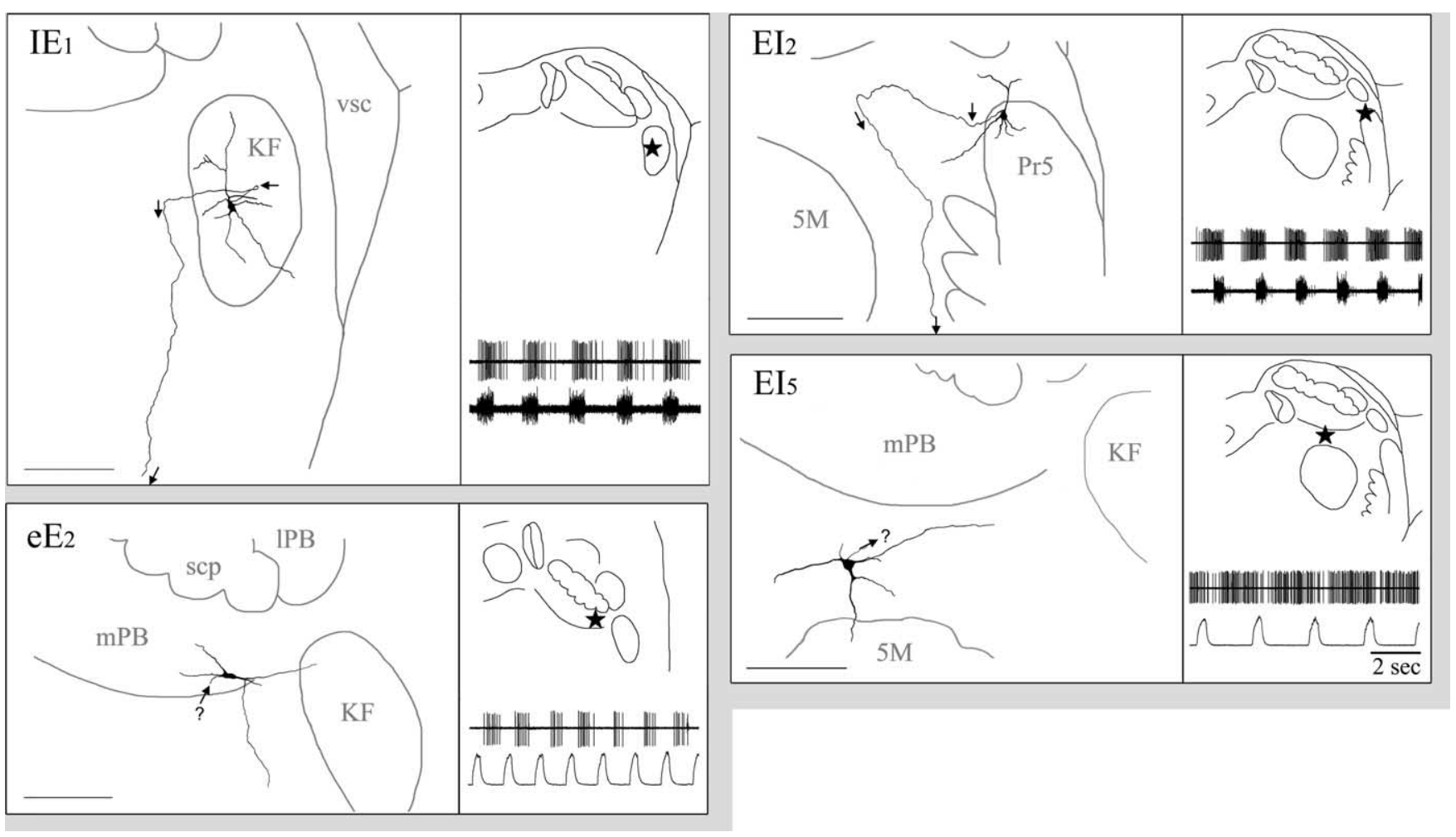

Figure 4. Somatic-dendritic-axonal domains of four labeled pneumotaxic neurons with type I dendritic trees. For each neuron, left is a camera lucida reconstructed drawing from three to seven consecutive $80 \mu \mathrm{m}$ sections (scale bar, $200 \mu \mathrm{m}$ ), and right is the drawing of a single Nissl-stained section showing precise soma location in dl-pons (star, top) and, for readers' convenience, a recap (bottom) of the corresponding neuronal discharge pattern as shown in Figure 2. Abbreviations are as in Figure 3. IE ${ }_{1}$, Inspiratory- expiratory phase-spanning neuron labeled in KF. This neuron has triangle soma, and the type I dendrite tree is primarily restricted within KF. The axon (arrow) arises from the foot of a primary dendrite. It goes laterally immediate after arising, then medially for a short distance, and finally turns ventrally to project toward vl-pons. $\mathrm{EE}_{2}$, Early-expiratory neuron labeled in $\mathrm{mPB}$. It has a fusiform soma and a simple type I dendritic tree. Arrow (with ? symbol) indicates suspected axon. El 2 , Expiratory-inspiratory phase-spanning neuron labeled in Pr5. It has an ovoid soma located in the dorsal margin of Pr5 and small dendritic tree composed of five short primary dendrites. Its axon arises from the foot of a primary dendrite and goes dorsomedially for a short distance and then turns ventrally to project toward vl-pons (arrows). El ${ }_{5}$, Expiratoryinspiratory neuron labeled in supratrigeminal nucleus. It has an ovoid soma and small dendritic tree composed of several short dendrites. Arrow (with ? symbol) indicates suspected axon. 5M, Trigeminal motor nucleus; scp, superior cerebellar peduncle.

cleus, newfound pneumotaxic areas such as IT and Pr5, painrelated areas such as $\mathrm{IPB}$, and dorsal subceruleus nucleus in which noradrenergic neurons abound. In particular, most of them had terminal dendrites extending laterally into the ventral spinocerebellar tract (vsc), an ascending pathway that conveys musculoskeletal information along with nociceptive afferents (see Discussion).

Four of the type II neurons had flat and elongated dendritic trees. Their somata were fusiform or ovoid, with dendrites originating from each end and extending in opposite directions. The length of the dendritic tree could reach $1000 \mu \mathrm{m}$ (average of 767 $\mu \mathrm{m}$ ), and the width could be as narrow as $150 \mu \mathrm{m}$ (average of 257 $\mu \mathrm{m})$, with an average length/width $(\mathrm{L} / \mathrm{W})$ ratio of 3.17. The other four neurons had either triangular or multipolar somata, with dendrites that extended in almost all directions. The average dimensions of the dendritic trees were $593 \times 448 \mu \mathrm{m}$ (L/W ratio of $\sim 1.32$ ).

\section{Type II dendrites display dendritic varicosities in vsc and other structures}

Dendrites of type I neurons were short and poorly branched, and all of them were smooth without appendages or varicosities. Dendrites of type II neurons did not branch extensively either. Often, a primary dendrite was seen to extend unbranched for a long distance at constant diameter. However, whereas the proximal sections of the primary dendrites were smooth and without ap- pendages or varicosities, the distal sections of primary and higher-order dendrites exhibited rich varicosities, which had varying diameters and could be regularly or irregularly spaced (Fig. 6). In particular, almost all of the terminal dendrites that invaded vsc showed varicosities that were connected by a thin dendritic segment, making them look like strings of beads (Fig. 6B).

\section{Type II dendrites display dendritic spines}

In three type II neurons $\left(\mathrm{IE}_{2}, \mathrm{EI}_{3}\right.$, and $\left.\mathrm{EI}_{4}\right)$, dendritic spines were clearly identified on distal primary or higher-order dendrites (Fig. 7). Most spines had thin necks protruding from the dendrites and bulb-like heads whose diameters varied from spine to spine. Some were just thorn-like protrusions without clear heads. The spine density was fairly low, ranging from 5 to 15 spines per dendrite, but noticeable.

\section{Pneumotaxic neurons send axonal projections to ventrolateral pons}

Axons of seven neurons covering all four major functional types were traced to relatively long distances. They arose from the corresponding somata or the initial segment of primary dendrites. The labeled axons were generally thin (diameter of $\sim 0.3-0.6 \mu \mathrm{m}$ in most cases) and lacked bifurcation; only one axon (Fig. 5, late $E_{2}$ ) was found to send out a medially projecting branch. Six axons projected medially or mediodorsally after arising but only for a short distance before turning ventrally to project toward the 

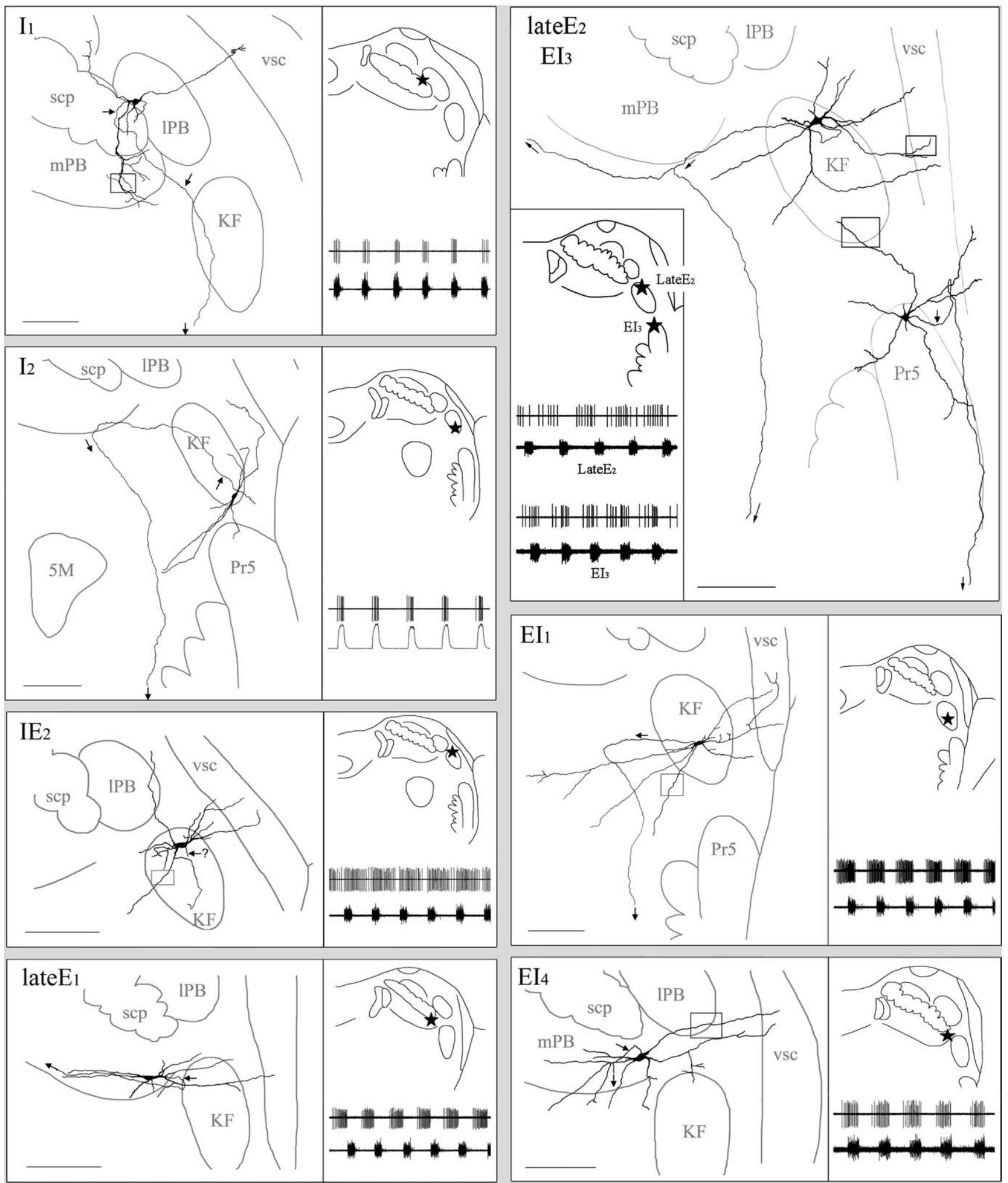

Figure 5. Somatic- dendritic-axonal domains of eight labeled pneumotaxic neurons with type II dendritic trees. Conventions are same as Figure 4. I, Inspiratory neuron labeled in external IPB. This neuron has a round soma located in external IPB, with type II dendrites extending into mPB, IPB, and vsc. The lateral and dorsomedial extending dendrites have few branches, but the ventral-extending dendrite branches repeatedly and exhibits rich varicosities after entering $\mathrm{mPB}$. The axon arises from the foot of a primary dendrite and projects ventrally toward vl-pons (arrows). Photomicrograph of the square area showing beaded dendrite in $\mathrm{mPB}$ is found in Figure $6 \mathrm{~A} . \mathrm{I}_{2}$, Inspiratory neuron labeled in ventral KF. It has a highly fusiform soma and elongated type II dendritic tree that extends ventromedially across $\mathrm{KF}$ into IT. The axon (arrow) arises from the foot of a primary dendrite and goes dorsomedially across $\mathrm{KF}$ to enter mPB, in which it turns ventrally to project through IT toward vl-pons. IE 2 , Inspiratory- expiratory phase-spanning neuron labeled in KF. This neuron has ovoid soma and an extensive type II dendritic tree that extends laterally into vsc. Dendritic spines were observed on dendrites in $\mathrm{KF}$ (for photomicrograph of the square area showing the dendritic spines, see Fig. 7A). Arrow (with ? symbol) indicates suspected axon. $\mathrm{Late}_{1}$, Late expiratory neuron labeled in $\mathrm{mPB}$. This neuron has fusiform soma and elongated type Il dendritic tree that is oriented mediolaterally. The medial extension of dendrites is within the boundary of $\mathrm{mPB}$, whereas the lateral extension cuts across $\mathrm{KF}$ to reach vsc. The axon arises from the foot of a lateral extending primary dendrite. It goes laterally for $\sim 100 \mu \mathrm{m}$ and then turns back to project medially along the long axis of the dendritic tree (arrows). Late $E_{2}$, Late expiratory neuron labeled in KF. This neuron has a triangle soma located (Figure legend continues.) 

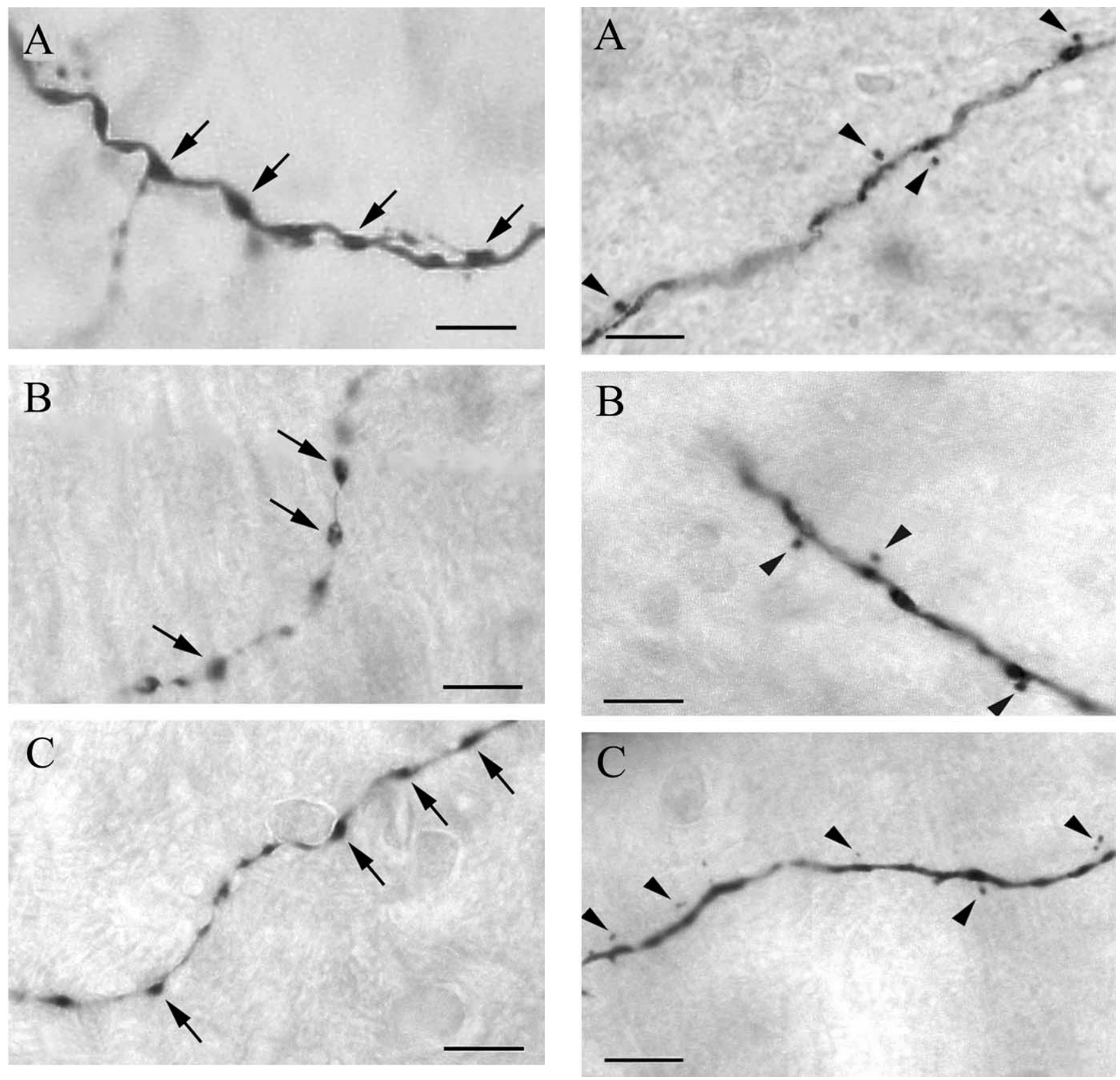

Figure 6. Photomicrographs showing dendritic varicosities (arrows) on terminal dendritic segments of the following: $A$, an inspiratory neuron labeled in IPB (photo taken from the square area of Fig. $5, I_{1}$, in $\mathrm{mPB}$, rotated $90^{\circ}$ counterclockwise); $\boldsymbol{B}$, an expiratory neuron labeled in $\mathrm{KF}$ (photo taken from the square area of Fig. 5 , LateE $_{2}$, in vsc); $\boldsymbol{C}$, an El neuron labeled in $\mathrm{KF}$ (photo taken from square area of Fig. $5, \mathrm{El}_{1}$, near KF). Scale bars, $10 \mu \mathrm{m}$.

Figure 7. Montage photomicrographs showing dendritic spines on dendritic segments of the following: $A$, an IE neuron labeled in $\mathrm{KF}$ (photo taken from the square area of Fig. $5, \mathrm{IE}_{2}$, in $\mathrm{KF}$ ); $\boldsymbol{B}$, an El neuron labeled in $\operatorname{Pr} 5$ (photo taken from the square area of Fig. $5, \mathrm{El}_{3}$, in KF); and $\boldsymbol{C}$, an El neuron labeled in $\mathrm{mPB}$ (photo taken from the square area of Fig. 5, El ${ }_{4}$, i IPB). The heads of the dendritic spines (arrowheads) are clearly visible in the photomicrographs (the corresponding necks were confirmed on separate focal planes). Scale bars, $10 \mu \mathrm{m}$.

$\leftarrow$

(Figure legend continued.) in dorsal KF. Its type II dendritic tree is composed of seven primary dendrites and associated branches, many of which extend laterally and dorsally beyond the dorsolateral boundary of KF into adjacent IPB and vsc. Distal dendrites and higher-order dendrites exhibit varicosities (for photomicrograph of the square area showing the dendritic varicosities, see Fig. $6 B$ ). The axon arises from the soma and goes medially to reach $\mathrm{mPB}$, in which it bifurcates into two branches: one branch continues going medially along the ventral margin of mPB, and the other turns ventrally to project toward vl-pons (arrows). El ${ }_{3}$, Expiratory-inspiratory phase-spanning neuron labeled in Pr5. This neuron has a multipolar soma located in the dorsal margin of Pr5. Its type II dendritic tree is composed of seven primary dendrites (five long and two short) and associated branches. Distal dendrites exhibit dendritic spines and varicosities (for photomicrograph of the square area showing the dendritic spines, see Fig. 7B). The axon (arrow) arises from the soma and goes laterally to reach the medial margin of middle cerebellar peduncle, in which it turns dorsally to travel for a short distance and then folds back to project ventrally along the lateral margin of Pr5. El ${ }_{1}$, Expiratory-inspiratory phase-spanning neuron labeled in KF. This neuron has an ovoid soma and a large type II dendritic tree composed of five long and two short primary dendrites and associated branches. The mediolateral span of the dendritic tree reaches $1 \mathrm{~mm}$, extending laterally into vsc and medially into dorsal subceruleus nucleus. Axon (arrow) arises from the soma and goes medially for $\sim 350 \mu \mathrm{m}$ before turning ventrally to project to vl-pons (for photomicrograph of the square area showing the dendritic varicosities, see Fig. 60). $\mathrm{El}_{4}$, Inspiratory neuron labeled in $\mathrm{mPB}$. The soma is ovoid, and its type ll dendritic tree is oriented mediolaterally. Dendrites extend medially across mPB into its adjacent ventral region and laterally across IPB to enter vsc. Dendritic spines can be observed on distal primary dendrites and higher-order dendrites (for photomicrograph of the square area showing the dendritic spines, see Fig. 70). The axon arises from the soma and projects medioventrally (arrows). 5M, Trigeminal motor nucleus; scp, superior cerebellar peduncle. 
A
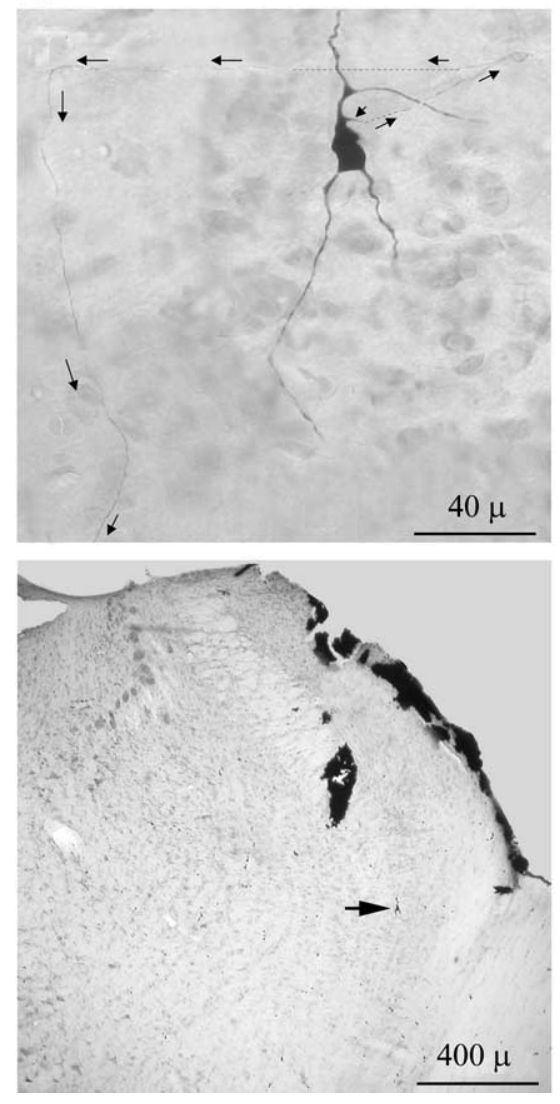

Figure 8. Montage photomicrographs of two labeled neurons showing axonal processes (arrows). $\boldsymbol{A}$, Top, Neuron $\mathrm{IE}_{1}$ with triangular soma has a well labeled axon arising from the foot of the dorsally extending primary dendrite. Dashed lines indicate sections that are too thin to be visible in the photomicrograph (taken under $40 \times$ objective) but were verified under high magnification ( $100 \times$ with oil-lens objective). The axon could be traced to vl-pons (see Fig. 4 , IE $E_{1}$ ). Bottom, photomicrograph taken under lower magnification ( $4 \times$ objective) showing the position of the soma (arrow) in KF. B, Top, Neuron $\mathrm{El}_{4}$ with ovoid soma has well labeled dendritic tree. The axon arises from the soma and could only be traced for a short distance (see Fig. 5, $\mathrm{EI}_{4}$ ). Bottom, Photomicrograph taken under lower magnification ( $4 \times$ objective) showing the position of the soma (arrow) in mPB.

vl-pons, usually via either IT or K nuclei, which are located between the trigeminal motor nucleus and Pr5. The other axon projected laterally and dorsally after arising and then turned back to project ventrally along the lateral margin of $\operatorname{Pr} 5$ toward vlpons. As a result of weakening of the labeling with distance, none of them were traced beyond the caudal and ventral margin of trigeminal motor nucleus.

Axons or axon-like processes were also observed in the remaining five neurons but only traced for short distances $(0.1-0.3$ $\mathrm{mm}$ ) and, hence, did not satisfy our identification criteria for axons (traced for $>0.5 \mathrm{~mm}$ ). Figure 8 shows the photomicrographs of two axons, one traced for a long distance (Fig. $8 \mathrm{~A}, \mathrm{IE}_{1}$ ) and the other for a short distance (Fig. $8 \mathrm{~B}, \mathrm{EI}_{4}$ ).

\section{Discussion}

To our knowledge, the present results provide the first systematic characterization of the discharge patterns of pneumotaxic neurons and their cytoarchitecture at the somatic, axonal, and dendritic levels in rats. The juxtacellular labeling technique allowed expeditious (compared with intracellular methods) characterization of respiratory neurons over a wide region in dl-pons. The 12 neurons we successfully labeled and reconstructed in detail included all four major functional types of pneumotaxic neurons and were distributed in five respiratory-related dl-pons subnuclei as established by previous studies. Thus, they should be generally representative of pneumotaxic neurons both functionally and morphologically. Such morphofunctional correlation at multiple levels of neural organization provides valuable insights about the role of the greater pneumotaxic center in integrating respiratory and nonrespiratory information.

\section{Functional taxonomy and topography of pneumotaxic neurons in rats}

In vagotomized decerebrated cats, pneumotaxic neurons in the $\mathrm{mPB}-\mathrm{KF}$ complex typically have relatively low discharge frequencies compared with medullary respiratory neurons, often in the form of tonic (nonphasic) discharges with varying degrees of respiratory modulations (Cohen and Wang, 1959; Bertrand et al., 1973; Bianchi and St John, 1982; Shaw et al., 1989; Gang et al., 1991; Dick et al., 1994). In contrast, the majority of pneumotaxic neurons we recorded in the $\mathrm{mPB}-\mathrm{KF}$ and other dl-pons regions in urethaneanesthetized rats showed a variety of phasic discharge patterns, many of which resembled closely their medullary counterparts (such as post-I and late-E). Some pneumotaxic neurons did exhibit seemingly sporadic or tonic discharges resembling the tonic or nonphasic neurons as reported in previous studies, but our quantitative $\mathrm{PEH}$ analysis showed that even these neurons demonstrated a dominant respiratory phasic component.

As with medullary respiratory neurons, the presently proposed functional taxonomy of pneumotaxic neurons provides a roadmap for further elucidation of the functional significance of these neurons in the future. In addition, the present juxtacellular labeling approach allowed much more precise definition of the loci of pneumotaxic neurons than conventional lesioning or dye microinjection methods used in previous studies. As in cats, these pneumotaxic neurons were often encountered in the lateral aspect of $\mathrm{mPB}$ and the KF nuclei, but some were also found in $\mathrm{PB}, \mathrm{IT}, \mathrm{Su} 5$, and Pr5. These findings suggest an expanded functional topography of the pneumotaxic center to include these dl-pons nuclei.

\section{Ventrolateral pons: an auxiliary pneumotaxic center?}

Remarkably, all labeled axons from pneumotaxic neurons $(n=$ 7) were traced to vl-pons in which the A5 noradrenergic neuron group is located. Although the labeling was unable to go beyond vl-pons, it is highly possible that these axonal projections were en route to the medulla, as suggested by previous neural tracing studies that demonstrated strong efferent projections from both dl-pons and vl-pons to the VRG and DRG (for review, see Song and Poon, 2004). These axons could also terminate or send out branches within vl-pons, as demonstrated by recent anterograde labeling (Dawid Milner et al., 2003) and orthodromic/antidromic electrostimulation (Jodkowski et al., 1994, 1997; Dawid Milner et al., 2001) studies. Thus, pneumotaxic neurons may modulate medullary respiratory neurons either directly through 
axons of passage via vl-pons or indirectly through relay neurons in vl-pons. This cytoarchitecture explains why electrical or chemical stimulation delivered at the vl-pons prolonged the expiratory phase and its lesioning or inhibition caused apneusis, as with mPB-KF (Jodkowski et al., 1994, 1997). As such, the vl-pons may be considered as auxiliary to the traditional pneumotaxic center in dl-pons.

\section{Pneumotaxic neurons integrate respiratory information in multiple dl-pons subnuclei}

Most of the pneumotaxic neurons we labeled were either located within $\mathrm{KF}$ or $\mathrm{mPB}$ or had dendrites extending into these areas. This cytoarchitecture enables those pneumotaxic neurons to interact with respiratory neurons in VRG and DRG, which are known to project reciprocally to $\mathrm{KF}$ and $\mathrm{mPB}$ nuclei (for review, see Ezure, 2004; Song and Poon, 2004). Some of the labeled pneumotaxic neurons had relatively small dendritic trees (type I; $n=$ 4) that were confined to the principal subnuclei in which the somata were located. These neurons could be the classic pneumotaxic relay neurons for integration of respiratory-related information as mentioned above.

However, the majority of our labeled respiratory neurons (type II; $n=8$ ) demonstrated long and beaded dendrites that went far beyond the corresponding principal subnuclei. For example, one of the inspiratory neurons (Fig. $5, \mathrm{I}_{1}$ ) whose soma was located in the $\mathrm{PB}$ had a large ventrally extending primary dendrite that passed through the superior cerebellar peduncle to enter the external $\mathrm{mPB}$, in which it became highly beaded and bifurcated several times to generate high-order dendrites that were again highly beaded (Fig. 6A). Apparently, this primary dendrite was to pick up respiratory-related information in the $\mathrm{mPB}$, although the soma was situated in $\mathrm{PPB}$. Such sprawling dendritic domains covering multiple respiratory-related subnuclei in dlpons enabled these pneumotaxic neurons to potentially access and integrate multiple respiratory-related inputs from various sources.

\section{Pneumotaxic neurons integrate pain and/or musculoskeletal information}

The somata and/or dendritic domains of some pneumotaxic neurons we identified were located in the IPB and KF nuclei, which are the terminating fields of some nociceptive afferents (Slugg and Light, 1994; Bourgeais et al., 2003). Recently, it was reported that certain respiratory rhythmic neurons in KF responded to cutaneous noxious stimuli and that the resulting respiratory enhancement was attenuated by bilateral inhibition of the parabrachial complex (Jiang et al., 2004). In addition, neurons in the lateral parabrachial nucleus were found to mediate the nociceptic cardiac response (Boscan et al., 2005). These physiologic observations combined with the present anatomic evidence strongly suggest that pneumotaxic neurons are capable of integrating nociceptive and respiratory-related information to coordinate respiratory movement with defensive somatic response.

Nociceptive afferents that terminate in IPB and KF are known to ascend to dl-pons along the vsc (Slugg and Light, 1994; Bourgeais et al., 2003). In the present study, we found that many type II dendrites extended laterally into vsc, in which the distal dendritic processes also exhibited considerably higher number of varicosities. This interesting cytoarchitecture of pneumotaxic neurons revealed in vivo is in agreement with the reported dendritic morphology of some $\mathrm{PBB}$ neurons observed in vitro (Herbert and Bellintani-Guardia, 1995). If such dendritic varicosities could be taken as the sites of synaptic contact as commonly as- sumed (Ellias and Stevens, 1980; Allen and Hopkins, 1988; Surkis et al., 1996), those pneumotaxic neurons would likely pick up information from nociceptive afferents that travel in parallel with vsc, perhaps by local terminal axonal bifurcation or branches arising from stem axons.

Alternatively, those pneumotaxic neurons might also pick up information from the vsc itself. The vsc, which terminates in the posterior vermal and paravermal lobules of the cerebellum, arises from various spinal interneuron groups. The latter receive "efference copies" of descending central commands reaching spinal motor neurons, as well as inputs from group Ia and group Ib afferents from muscle spindles and tendons. Thus, the vsc relays information about skeletal muscles activity to the cerebellum, which, in turn, uses this information to refine and coordinate the ongoing somatic movements (Lundberg, 1971; Arshavsky et al., 1972; Grant and $\mathrm{Xu}, 1988$ ). It is well known that the respiratory rhythm could be entrained to somatic locomotor rhythm (Iscoe and Polosa, 1976; Iscoe, 1981; Ainsworth et al., 1996).

Recently, Potts et al. (2005) made the important observation that such respiratory entrainment by afferents from skeletal muscles was eliminated after lesion or inhibition of the dorsolateral parabrachial nucleus, indicating a vital role for the latter in synchronizing respiratory movement with rhythmic somatic movement. Pneumotaxic neurons with dendrites extending into vsc as revealed in the present study potentially have access to both respiratory-related information and somatic movement-related information. It is of interest for future studies to ascertain whether and how these type II dendrites from pneumotaxic neurons make contacts with movement-related and/or nociceptive afferents at the level of vsc.

\section{Pneumotaxic neurons integrate trigeminal information}

In the present study, we recorded and labeled some respiratory neurons in Pr5, IT, and Su5 and observed the dendritic invasion of these trigeminal structures (mainly IT and Pr5) by respiratory neurons in KF. These pneumotaxic neurons may contribute to the reported influences of IT and/or Pr5 on respiration in anesthetized rats (Chamberlin and Saper, 1994, 1998) or in sleep (Radulovacki et al., 2004). Alternatively, these pneumotaxic neurons could be involved in coordinating respiration with trigeminal functions. In rats, the Pr5 relays sensory information from whiskers and other facial tactile sensors to the thalamus. The pneumotaxic neurons in Pr5 may potentially integrate this information with respiratory-related information and contribute to the reported synchronization of whisker movements with respiration (Welker, 1964; Hattox et al., 2003).

Conversely, the IT and Su5 comprise trigeminal premotor neurons (Li et al., 1995). Motor neurons of the tensor veli palatini that contract during the inspiratory phase to maintain nasopharyngeal isthmus patency are located in the trigeminal motor nucleus (Anch et al., 1981). Thus, the pneumotaxic neurons in IT and Su 5 may participate in the control of upper airway patency by modulating the contraction of tensor veli palatini.

As well, the IT and KF receive projections from the spinal trigeminal nucleus caudalis (Chamberlin and Saper, 1998), which in turn receives multi-modalities of sensory inputs from upper airway structures, such as tongue, oropharyngeal, and nasal mucosa (Shigenaga et al., 1986; Anton and Peppel, 1991). For example, stimulation of the ethmoidal nerve that innervates the nasal mucosa induced c-Fos expressions in KF and IT (Dutschmann and Herbert, 1997). Thus, pneumotaxic neurons in the $\mathrm{KF}$ and those in the IT that we recorded may likely integrate such trigeminal information with respiratory information to coordi- 
nate protective respiratory reflexes, such as sneeze, cough, and diving reflex (Dutschmann and Herbert, 1996).

\section{Dendritic spines: a neuronal substrate for synaptic plasticity in pneumotaxic neurons?}

To our knowledge, this is the first documented evidence of dendritic spines or spine-like structures on functionally identified respiratory-related neurons in the mammalian brainstem. The three labeled neurons $\left(\mathrm{IE}_{2}, \mathrm{EI}_{3}\right.$, and $\mathrm{EI}_{4}$; all type II) with dendritic spines were, respectively, found in KF, Pr5, and $\mathrm{mPB}$. Considering the technical limitation of juxtacellular labeling in revealing fine details of dendrites (Pilowsky and Makeham, 2001), the actual proportion of pneumotaxic neurons with dendritic spines could be even higher than the one-fourth presently reported. In hippocampus and cerebral cortex, dendritic spine is a postsynaptic specialization that receives excitatory synaptic inputs and is important for the induction of synaptic plasticity (Nimchinsky et al., 2002; Hayashi and Majewska, 2005). The present discovery of dendritic spines and spine-like protrusions in some pneumotaxic neurons suggests a possible neuronal correlate for the learning and memory processes evident in the Hering-Breuer reflex and carotid chemoreflex (Poon and Siniaia, 2000; Siniaia et al., 2000; Young et al., 2003; Poon, 2004).

\section{A new definition of pneumotaxic center}

In conclusion, the present findings shed new light on the functional and structural organization of the pneumotaxic center. Pontine neurons with a variety of respiratory phasic discharge patterns are found in traditional pneumotaxic regions (KF and $\mathrm{mPB}$ ) and other dl-pons subnuclei (IPB, Pr5, IT, and Su5). These neurons send axons to vl-pons and beyond and have dendrites that extend into adjacent pneumotaxic or other dl-pons areas. These findings challenge the conventional definition of the pneumotaxic center and suggest a broader topographic organization that includes not only the loci of the pneumotaxic neurons but also their dendritic domains and axonal projections across multiple respiratory or nonrespiratory regions in dl-pons and vlpons. In particular, the dendritic invasion into vsc allows these pneumotaxic neurons to potentially integrate respiratory-related information with those about somatic nociception or motor activities to coordinate the control of respiratory output. Similarly, the demonstrated presence of pneumotaxic neurons in $\mathrm{PB}$ and in Pr5, IT, and Su5 suggests the possible integration of nociceptive and trigeminal information in these dl-pons nuclei, respectively. Finally, the present discovery of dendritic spines or spine-like structures on some pontine pneumotaxic neurons lends additional support to the postulated role of synaptic plasticity in pontine integration of such pneumotaxic information.

\section{References}

Ainsworth DM, Smith CA, Henderson KS, Dempsey JA (1996) Breathing during exercise in dogs-passive or active? J Appl Physiol 81:586-595.

Alheid GF, Milsom WK, McCrimmon DR (2004) Pontine influences on breathing: an overview. Respir Physiol Neurobiol 143:105-114.

Allen GV, Hopkins DA (1988) Mamillary body in the rat: a cytoarchitectonic, Golgi, and ultrastructural study. J Comp Neurol 275:39-64.

Anch AM, Remmers JE, Sauerland EK, Degroot WJ (1981) Oropharyngeal patency during walking and sleep in the Pickwickian syndrome: electromyographic activity of the tensor veli palatini. Electromyogr Clin Neurophysiol 21:317-330.

Anton F, Peppel P (1991) Central projections of trigeminal primary affer- ents innervating the nasal mucosa: a horseradish peroxidase study in the rat. Neuroscience 41:617-628.

Arshavsky YI, Berkinblit MB, Fukson OI, Gelfand IM, Orlovsky GN (1972) Origin of modulation in neurones of the ventral spinocerebellar tract during locomotion. Brain Res 43:276-279.

Bertrand F, Hugelin A, Vibert JF (1973) Quantitative study of anatomical distribution of respiration related neurons in the pons. Exp Brain Res 16:383-399.

Bianchi AL, St John WM (1982) Medullary axonal projections of respiratory neurons of pontile pneumotaxic center. Respir Physiol 48:357-373.

Borday V, Kato F, Champagnat J (1997) A ventral pontine pathway promotes rhythmic activity in the medulla of neonate mice. NeuroReport 8:3679-3683.

Boscan P, Dutschmann M, Herbert H, Paton JF (2005) Neurokininergic mechanism within the lateral crescent nucleus of the parabrachial complex participates in the heart-rate response to nociception. J Neurosci 25:1412-1420.

Bourgeais L, Gauriau C, Monconduit L, Villanueva L, Bernard JF (2003) Dendritic domains of nociceptive-responsive parabrachial neurons match terminal fields of lamina I neurons in the rat. J Comp Neurol 464:238-256.

Chamberlin NL, Saper CB (1994) Topographic organization of respiratory responses to glutamate microstimulation of the parabrachial nucleus in the rat. J Neurosci 14:6500-6510.

Chamberlin NL, Saper CB (1998) A brainstem network mediating apneic reflexes in the rat. J Neurosci 18:6048-6056.

Cohen MI, Wang SC (1959) Respiratory neuronal activity in pons of cat. J Neurophysiol 22:33-50.

Dawid Milner MS, Lara JP, Gonzalez-Baron S, Spyer KM (2001) Respiratory effects of stimulation of cell bodies of the A5 region in the anaesthetised rat. Pflügers Arch 441:434-443.

Dawid Milner MS, Lara JP, Lopez de Miguel MP, Lopez-Gonzalez MV, Spyer KM, Gonzalez-Baron S (2003) A5 region modulation of the cardiorespiratory responses evoked from parabrachial cell bodies in the anaesthetised rat. Brain Res 982:108-118.

Dick TE, Bellingham MC, Richter DW (1994) Pontine respiratory neurons in anesthetized cats. Brain Res 636:259-269.

Dick TE, Jodkowski JS, Coles SK (1995) A "pneumotaxic center" in the ventrolateral pons of rats. In: Ventral brainstem mechanisms and control of respiration and blood pressure (Trouth CO, Millis RM, Kiwull-Schone HF, Schlafke ME, eds), pp 723-737. New York: Dekker.

Dutschmann M, Herbert H (1996) The Kolliker-Fuse nucleus mediates the trigeminally induced apnoea in the rat. NeuroReport 7:1432-1436.

Dutschmann M, Herbert H (1997) Fos expression in the rat parabrachial and Kolliker-Fuse nuclei after electrical stimulation of the trigeminal ethmoidal nerve and water stimulation of the nasal mucosa. Exp Brain Res 117:97-110.

Ellias SA, Stevens JK (1980) The dendritic varicosity: a mechanism for electrically isolating the dendrites of cat retinal amacrine cells? Brain Res 196:365-372.

Ezure K (2004) Respiration-related afferents to parabrachial pontine regions. Respir Physiol Neurobiol 143:167-175.

Gang S, Mizuguchi A, Aoki M (1991) Axonal projections from the pontine pneumotaxic region to the nucleus raphe magnus in cats. Respir Physiol 85:329-339.

Grant G, Xu Q (1988) Routes of entry into the cerebellum of spinocerebellar axons from the lower part of the spinal cord. An experimental anatomical study in the cat. Exp Brain Res 72:543-561.

Hattox A, Li Y, Keller A (2003) Serotonin regulates rhythmic whisking. Neuron 39:343-352.

Hayashi Y, Majewska AK (2005) Dendritic spine geometry: functional implication and regulation. Neuron 46:529-532.

Herbert H, Bellintani-Guardia B (1995) Morphology and dendritic domains of neurons in the lateral parabrachial nucleus of the rat. J Comp Neurol 354:377-394.

Iscoe S (1981) Respiratory and stepping frequencies in conscious exercising cats. J Appl Physiol 51:835-839.

Iscoe S, Polosa C (1976) Synchronization of respiratory frequency by somatic afferent stimulation. J Appl Physiol 40:138-148.

Jacquin TD, Borday V, Schneider-Maunoury S, Topilko P, Ghilini G, Kato F, Charnay P, Champagnat J (1996) Reorganization of pontine rhythmogenic neuronal networks in Krox-20 knockout mice. Neuron 17:747-758. 
Jiang M, Alheid GF, Calandriello T, McCrimmon DR (2004) Parabrachiallateral pontine neurons link nociception and breathing. Respir Physiol Neurobiol 143:215-233.

Jodkowski JS, Coles SK, Dick TE (1994) A "pneumotaxic centre" in rats. Neurosci Lett 172:67-72.

Jodkowski JS, Coles SK, Dick TE (1997) Prolongation in expiration evoked from ventrolateral pons of adult rats. J Appl Physiol 82:377-381.

Li YQ, Takada M, Kaneko T, Mizuno N (1995) Premotor neurons for trigeminal motor nucleus neurons innervating the jaw-closing and jawopening muscles: differential distribution in the lower brainstem of the rat. J Comp Neurol 356:563-579.

Lumsden $\mathrm{T}$ (1923) Observations on the respiratory centres in the cat. J Physiol (Lond) 57:153-160.

Lundberg A (1971) Function of the ventral spinocerebellar tract. A new hypothesis. Exp Brain Res 12:317-330.

Mulkey DK, Stornetta RL, Weston MC, Simmons JR, Parker A, Bayliss DA, Guyenet PG (2004) Respiratory control by ventral surface chemoreceptor neurons in rats. Nat Neurosci 7:1360-1369.

Nimchinsky EA, Sabatini BL, Svoboda K (2002) Structure and function of dendritic spines. Annu Rev Physiol 64:313-353.

Paxinos G, Watson C (1986) The rat brain in stereotaxic coordinates, Ed 2. New York: Academic.

Pilowsky PM, Makeham J (2001) Juxtacellular labeling of identified neurons: kiss the cells and make them dye. J Comp Neurol 433:1-3.

Pinault D (1996) A novel single-cell staining procedure performed in vivo under electrophysiological control: morpho-functional features of juxtacellularly labeled thalamic cells and other central neurons with biocytin or Neurobiotin. J Neurosci Methods 65:113-136.

Poon CS (2004) Organization of central pathways mediating the HeringBreuer reflex and carotid chemoreflex. In: Post-genomic perspectives in modeling and control of breathing (Champagnat J, Denavit-Saubie M, Fortin G, Foutz AS, Thoby-Brisson M, eds). Paris: Kluwer/Plenum.

Poon CS, Siniaia MS (2000) Plasticity of cardiorespiratory neural processing: classification and computational functions. Respir Physiol 122:83-109.

Potts JT, Rybak IA, Paton JF (2005) Respiratory rhythm entrainment by somatic afferent stimulation. J Neurosci 25:1965-1978.
Radulovacki M, Pavlovic S, Carley DW (2004) Pontine intertrigeminal region attenuates sleep apneas in rats. Sleep 27:383-387.

Shaw CF, Cohen MI, Barnhardt R (1989) Inspiratory-modulated neurons of the rostrolateral pons: effects of pulmonary afferent input. Brain Res 485:179-184

Shigenaga Y, Chen IC, Suemune S, Nishimori T, Nasution ID, Yoshida A, Sato H, Okamoto T, Sera M, Hosoi M (1986) Oral and facial representation within the medullary and upper cervical dorsal horns in the cat. J Comp Neurol 243:388-408.

Siniaia MS, Young DL, Poon CS (2000) Habituation and desensitization of the Hering-Breuer reflex in rat. J Physiol (Lond) 523:479-491.

Slugg RM, Light AR (1994) Spinal cord and trigeminal projections to the pontine parabrachial region in the rat as demonstrated with Phaseolus vulgaris leucoagglutinin. J Comp Neurol 339:49-61.

Song G, Poon CS (2003) Morphology of respiratory neurons in dorsolateral pons revealed by juxtacellular labeling in rat. Soc Neurosci Abstr 29:503.17.

Song G, Poon CS (2004) Functional and structural models of pontine modulation of mechanoreceptor and chemoreceptor reflexes. Respir Physiol Neurobiol 143:281-292.

Song G, Zhuang D, Poon C (2004) Anterograde tracing of bilateral axonal projections from dorsolateral pons to respiratory-related brainstem regions in rats. Soc Neurosci Abstr 30:661.1.

Surkis A, Taylor B, Peskin CS, Leonard CS (1996) Quantitative morphology of physiologically identified and intracellularly labeled neurons from the guinea-pig laterodorsal tegmental nucleus in vitro. Neuroscience 74:375-392.

von Euler C (1986) Brain stem mechanisms for generation and control of breathing pattern. In: Handbook of physiology, Vol II, Sec 3 (Fishman AP, Cherniack NS, Widdicombe JG, Geiger SR, eds), pp 1-67. Bethesda: American Physiological Society.

Welker WI (1964) Analysis of sniffing of the albino rat. Behaviour 22:223-244.

Young DL, Eldridge FL, Poon CS (2003) Integration-differentiation and gating of carotid afferent traffic that shapes the respiratory pattern. J Appl Physiol 94:1213-1229. 